\title{
New eyewear regulations draw ire of optometrists
}

Published at www.cmaj.ca on May 4

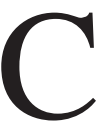

hanges to eyewear regulations in British Columbia have drawn praise from some opticians and consumers, but most Canadian optometrists consider them a poke in the eye.

Two amended regulations in particular have become topics of debate (see sidebar for a more complete list). One allows opticians to conduct independent sight tests to determine prescriptions. (Previously, opticians had to send test results to physicians for review.) The other removes the requirement for online sellers of eyewear to verify their customers' prescriptions. The changes, which came into effect May 1, were announced by BC Health Services Minister Kevin Falcon on Mar. 19.

"Advances in technology have made $\mathrm{BC}$ 's current regulations regarding the dispensing of eyewear obsolete and we are simply modernizing the system to enhance patient choice while maintaining public safety," Brian Cotton, a spokesman for the BC Ministry of Health Services, writes in an email.

Optician-led sight tests are fully automated, and innovations in technology have made physician review an unnecessary extra step, wrote Cotton. Optometry associations, however, have noted that sight tests measure only refraction, to determine prescription strength, and do not take into account overall eye health. But according to the $\mathrm{BC}$ government, the risk of eye health problems is low for people aged 19-65.

"Ministry staff have examined the medical evidence and have determined there is no strong scientific evidence that regular eye health examinations for asymptomatic individuals between the ages of 19 and 65 improve health outcomes," Cotton wrote in his email, adding that the "health and safety of British Columbians is always a primary concern and we would not be making changes if we thought it put

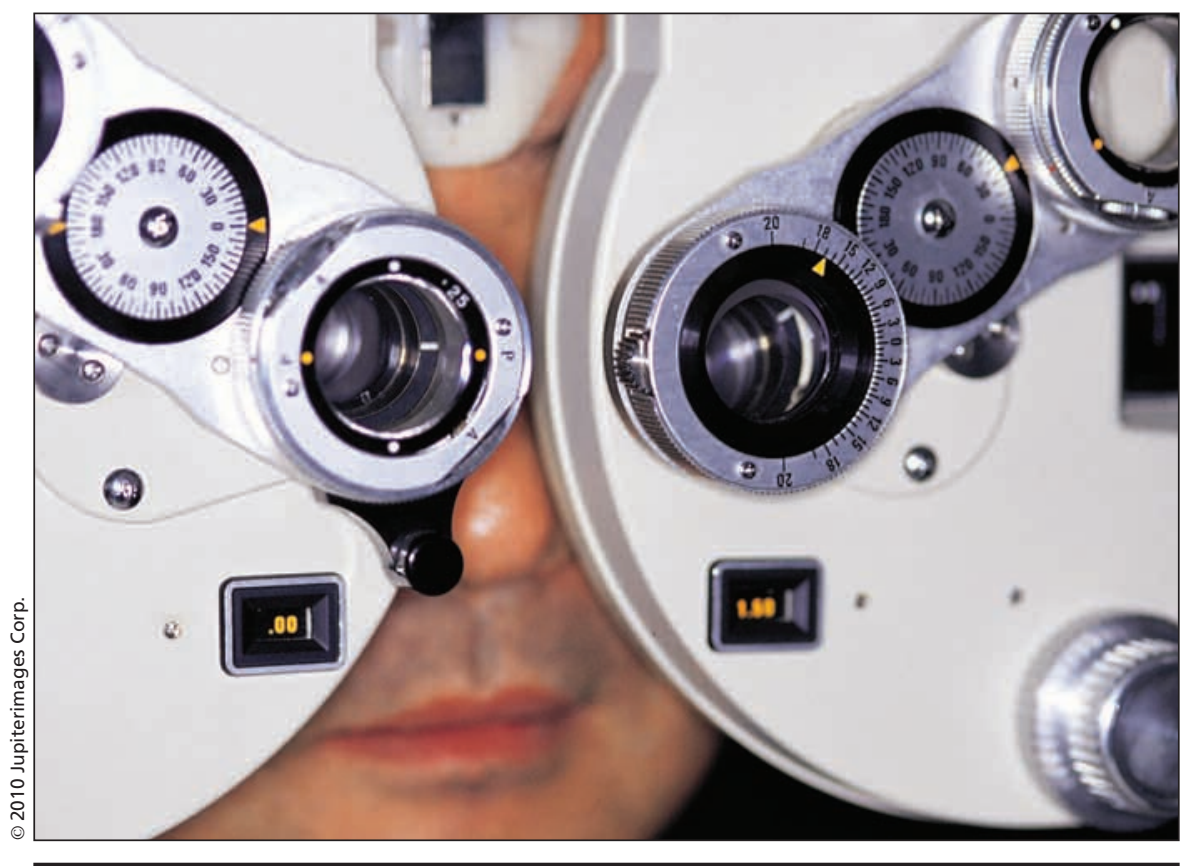

The British Columbia government says that advances in technology justify allowing opticians to conduct independent sight tests.

anyone's health and safety at risk. Opticians have been doing sight-tests in BC since about 1997 and there are now more than 100 sight-testing locations across the province."

Kirsten North, president of the Canadian Association of Optometrists, says that automated sight tests aren't comprehensive. "The main issue we have is that asymptomatic eye disease will go unchecked," she says.

For some eye diseases, such as glaucoma, early detection is the only way to prevent permanent damage. Symptoms occur late and lost vision cannot be recovered. Sight tests are also unable to detect problems such as retinal tears, corneal scars and eye tumours.

Automated sight tests, alone, aren't an adequate basis on which to generate prescriptions, says North. Factors other than refraction, such as age and health status, must be considered. "Even something as simple as how tall someone is can affect a prescription," she says.

Canadian optometrists are also displeased that $\mathrm{BC}$ has become the first jurisdiction in North America to allow online companies to sell eyeglasses and contact lenses without verifying prescriptions. While they don't object to people having the option of buying eyewear online, optometrists do object to eyewear being treated like any other consumer product. Some have reminded Falcon in writing that Health Canada still designates contact lenses as medical devices.

"These types of buyer-beware regulations are not appropriate for health care products," says Antoinette Dumalo, president of the British Columbia Association of Optometrists. "Consumer choice needs to be balanced with protection of the public."

Optometry associations aren't alone in their concern. Falcon has been receiving a steady stream of letters since announcing the changes to eyewear regulations. The CNIB wrote a letter claiming that because of the changes, the "vision health of British Columbians may be at risk." The Canadian Diabetes Association also wrote a 
letter to Falcon, expressing their concern that people with diabetes might now have fewer complete eye exams. This will result in "unintended negative consequences," the letter stated, including an increase in cases of the eye disease diabetic retinopathy.

Thomas Freddo, director of the School of Optometry at the University of Waterloo in Ontario, wrote a scathing letter to Falcon, accusing him of putting the interests of a single BC company (Coastal Contacts, an online eyewear seller with 120 employees) above the vision health of $\mathrm{BC}$ residents. He claimed that performing only standalone sight tests is "analogous to checking the dipstick in your car and using the oil level as assurance that the transmission, the brakes, the suspension, the steering and the tires, the wipers, the headlights and emissions are all fine."

Freddo also ridiculed Falcon's claim that his staff had "scoured" medical literature before amending eyewear regulations. "It looks at though your staff may have confused the various definitions of 'scour' when they 'scoured' the literature and selected the definition 'to clean or polish by vigorous rubbing with abrasives, to make things on the surface appear clean and bright," he wrote.

Conversely, there's been silence from the word processors of opticians. According to Nick Atkinson, registrar of the College of Opticians of British Columbia, these regulation changes have been a long time coming, stemming from consultations dating back to 1992. With respect to eliminating doctor review for sight tests, Atkinson doesn't see what all the fuss is about. "I don't think it's a dramatic change at all," he says. "It just eliminates that extra step."

Robert Dalton, president and executive director of the Opticians Association of Canada, notes that opticians in $\mathrm{BC}$ have been conducting sight tests for 12 years and are fully capable of conducting them independently. And

According to the BC Ministry of Health Services, the May 1 changes to the regulations for opticians and optometrists under the Health Professions Act include:

- Removal of most of the restrictions that allow only opticians or optometrists, or workers supervised by them, to dispense glasses or contacts.

- Allowing prescriptions issued by medical doctors and optometrists outside of the province to be filled within $\mathrm{BC}$

- Allowing people to order glasses or contacts online without having to give the seller a copy of their prescription, sight test assessment or contact lens specifications.

- Requiring opticians and optometrists in $\mathrm{BC}$ to include in a prescription or sight-test assessment the measurement of distance between the client's pupils, which is required for the proper fitting of glasses.

- Requiring opticians and optometrists in BC to give clients, free of charge, a copy of their prescription, sight-test assessment or contact lens specifications - whether or not it is requested by the client - and also to give a copy, free of charge, to a third-party eyewear seller or other person if requested by the client.

- Allowing opticians to independently conduct sight-tests for healthy clients aged 19-65.

allowing them to do so is better for consumers. "It unbundles the eye exam," he says. "Any time you unbundle a health care process, it makes it more affordable and allows consumers to have more choices."

Sight tests are also conducted by opticians in other provinces, including Alberta and Ontario. The pushback from optometrists is to be expected, says Dalton, because increasing the scope of practice for opticians infringes on their territory. Dalton is concerned, however, about the elimination of prescription verification for online eyewear sellers, claming that the elderly and children are particularly at risk. Still, he says, it's unlikely that people in those groups will be getting their eye-care needs met online.

"I don't see the public going online to buy glasses for two-year-olds," he says. Like Dalton, Sara Moshurchak, president of Opticians of British Columbia, is concerned about the deregulation of online eyewear sellers. Though in the end, she says, it just means eye health professionals will have to make a greater effort to educa- tion the public about the importance of proper eye care.

As for the elimination of physician review for sight tests, Moshurchak says it is a positive development for her profession. "All in all, what is really great is we are being officially recognized as professionals," she says. "Increasing our scope of practice is going to allow us to thrive."

Ira Mitchell, curator of GlassyEyes, a popular US blog about buying eyeglasses online, believes all the amended regulations will prove beneficial to BC residents. In his opinion, optical professionals are likely more concerned about losing revenue than the potential for increased cases of glaucoma or blindness.

"I predict that eye health will be better in British Columbia in five years than it is now," Mitchell wrote in his email. "People are more apt to keep current in a more open and competitive environment. The only losers are the opticians and optometrists who fail to adapt." — Roger Collier, CMAJ

DOI:10.1503/cmaj.109-3252 